NBER WORKING PAPER SERIES

\title{
DOES COMPETITION ELIMINATE DISCRIMINATION? EVIDENCE FROM THE COMMERCIAL SEX MARKET IN SINGAPORE
}

\author{
Huailu Li \\ Kevin Lang \\ Kaiwen Leong \\ Working Paper 20911 \\ http://www.nber.org/papers/w20911 \\ NATIONAL BUREAU OF ECONOMIC RESEARCH \\ 1050 Massachusetts Avenue \\ Cambridge, MA 02138 \\ January 2015
}

We are very grateful to Claudia Olivetti, Andrew Oswald, Johannes Schmieder and seminar participants at the Asian meeting of the Econometrics Society, Boston University, Georgetown University (Doha), Nanyang Technological University, the National University of Singapore, the Singapore Economic Review Conference, Cornell University, Duke University and NBER Labor Studies for their helpful comments. Leong also thanks Nanyang Technological University for start-up funding and its support for this research while Lang acknowledges funding from the National Science Foundation under grant SES-1260197. The usual caveat applies. The views expressed herein are those of the authors and do not necessarily reflect the views of the National Bureau of Economic Research.

NBER working papers are circulated for discussion and comment purposes. They have not been peerreviewed or been subject to the review by the NBER Board of Directors that accompanies official NBER publications.

(C) 2015 by Huailu Li, Kevin Lang, and Kaiwen Leong. All rights reserved. Short sections of text, not to exceed two paragraphs, may be quoted without explicit permission provided that full credit, including (C) notice, is given to the source. 
Does Competition Eliminate Discrimination? Evidence from the Commercial Sex Market in Singapore

Huailu Li, Kevin Lang, and Kaiwen Leong

NBER Working Paper No. 20911

January 2015

JEL No. J7,O17

\section{ABSTRACT}

The street sex worker market in Geylang, Singapore is highly competitive. Clients can search legally at negligible cost. Sex workers discriminate based on client ethnicity despite an excess supply of sex workers. Workers are more (less) likely to approach and ask a higher (lower) price of Caucasians (Bangladeshis), based on their perceived willingness to pay. They avoid Indians, set a significantly higher price and are less likely to reach an agreement with them, suggesting that Indians face taste discrimination. These findings remain even after controlling for prostitute fixed effects and are consistent with the workers' self-reported attitudes and beliefs.

Huailu Li

School of Economics

Fudan University

600 Guoquan Road

Shanghai, 200433,

People's Republic of China

huailu@bu.edu

Kevin Lang

Department of Economics

Boston University

270 Bay State Road

Boston, MA 02215

and NBER

lang@bu.edu
Kaiwen Leong

School of Humanities and Social Sciences

Nanyang Technological University

14 Nanyang Drive

Singapore 637332

kleong@ntu.edu.sg 


\section{Introduction}

In the canonical economic model of discrimination, Becker (1957), competition eliminates discrimination. More generally, under competition the law of one price prevails. Comparable workers in similar jobs must be paid the same wage; consumers must pay the same price for a homogeneous good. In contrast, Diamond (1971) shows that with sequential search even a very small search cost creates an equilibrium in which firms set the monopoly price (or offer the monopsony wage as in Black (1995)). This, in turn, implies that customers with a higher willingness to pay will be charged a higher price and that sellers can, within limits described below, indulge discriminatory tastes.

We use an apparently highly competitive market, the market for street sex workers in Singapore, to test these competing theories. During "usual business hours" sex workers are readily available; times between meetings are no more than two to five minutes. Potential customers are at no legal risk, and the social risk is small because the sex workers operate in an area regularly frequented by individuals who are on neither side of the sex trade. Thus search costs are very low but nonzero.

While clearly there is some heterogeneity among sex workers, we can control for sex worker fixed effects. Moreover, our qualitative interviews suggest that this heterogeneity is relatively unimportant. We would anticipate that, especially within a narrow segment of the sex market, the importance of worker heterogeneity for a brief sexual encounter would be small relative to worker heterogeneity in standard employment relationships. The setting is almost ideal for contrasting the two theories.

We find that sex workers use ethnicity to discriminate based on the client's willingness to pay, which we term statistical discrimination. To a lesser degree, they also discriminate against ethnic groups with darker skin tones (taste discrimination). Some of the sex workers justify their dislike of Indians, the primary group with darker skin, by claiming that they bargain harder, want longer service duration or are more prone to violence. We find no evidence of harder bargaining or of longer service duration and find that Indians have a relatively low demand for forms of sex that the sex workers find more unpleasant. However, we cannot completely rule out the violence explanation.

There is considerable evidence of discriminatory behaviors by firms. Audit and correspondence studies (e.g. Ayres and Siegelman, 1995; Neumark, 1996; Bertrand and Mullainathan, 2004) consistently find differential treatment of men and women and of blacks and whites. However, as Heckman and Siegelman (1993) and Heckman (1998) argue, such studies can reveal discriminatory behaviors but not whether the 
equilibrium is discriminatory. Unlike the "applicants" in such studies, workers and consumers do not apply to firms randomly. Potential objects of discrimination may know how to avoid transacting with prejudiced individuals or have sufficiently frequent opportunities for transactions to eliminate any impact on transaction prices. In addition, in audit studies it is impossible to ensure that testers differ only with respect to race or sex. Since the number of testers is typically small, it is often difficult, if not impossible, to know whether they also differ on some dimension other than the one intended by the researchers. For example, Castillo et al's (2013) intriguing study of taxis in Lima, Peru relies on six male and sex female testers. ${ }^{1}$ Similar problems can even arise in correspondence studies. Jacquemet and Yannelis (2012) find considerable within-race variation in callback rates for different names. Kristen was called back at a rate three times that of Laurie, and Ebony at three times that of Lakisha and almost twice that of Laurie.

These concerns have generated interest in studies that can capture discrimination in actual transactions prices by regular participants in markets. There are very interesting studies of on-line markets (Zussman (2013); Doleac and Stein (2013) and Pope and Sydnor (2011)), but these are likely to differ from discrimination in faceto-face encounters with more visual and verbal clues. Thus, List (2004) uses the natural setting of the sportscard trading platform and real market participants to identify the existence and nature of discrimination. In this setting, there is some risk that because the experimenter influences the interactions, he biases the results. It would be preferable, if possible, to observe a large number of naturally occurring transactions.

This is the approach followed by Graddy (1995) who finds price discrimination in favor of Asians and against whites in one wholesaler's sales of whiting at the Fulton Fish Market in New York. She suggests that, because of the markets in which they resell the whiting, demand for whiting is more elastic among Asians. Our approach is, in many ways, similar to Graddy's. However, we examine a market with a very large number of sellers. In contrast, only six wholesalers carried whiting at FFM, and the sellers are careful not to announce prices, making it easier for them to avoid competition.

Bayer, Casey, Ferreira, and McMillan (2012) is in some ways the study closest to ours in that it studies a large number of transactions in the housing market. After controlling for a large number of factors, including housing unit, the authors find that black and Hispanic homebuyers pay a premium of roughly three percent. This

\footnotetext{
${ }^{1}$ The authors do allow for random tester effects, but as discussed in Donald and Lang (2007), such techniques are only appropriate when the number of clusters (in this case testers) is large.
} 
difference while nontrivial is also modest and occurs in a market in which there is often little face-to-face interaction between buyers and sellers.

We investigate price discrimination based on ethnicity in a market with a large number of nearly identical sex workers selling homogeneous services to clients who search at negligible cost. We collected data on both sex workers and their recent transactions, recording information only after the transaction so as to avoid interfering. We combine this with rich survey and ethnographic data. In interviews, the sex workers revealed that they price services differently based on the client's ethnicity, which they take as a signal of the client's willingness to pay. They tend to actively approach whites, Japanese, and Koreans, the ethnic groups whom they believe to be wealthier, and inflate the prices quoted to these clients. On the other hand, sex workers express animus towards ethnic groups with darker skin tones. They report that they avoid these clients (such as Indians) or ask for a higher price to compensate for the disutility of working with them. The former hints at statistical price discrimination (Arrow, 1973; Phelps, 1972), while the latter suggests taste-based discrimination.

We build a simple model in which sex workers approach the potential client and offer him a take-it-or-leave-it price. Clients engage in sequential search until they meet a sex worker with an acceptable combination of price and match-specific quality. We show that if a sex worker believes a client has a high willingness to pay, she will be more likely to approach, set a higher price and be more likely to have her price accepted. This is consistent with what we observe for whites and, in the opposite direction, Bangladeshis. On the other hand, if she is driven by distaste, she will be less likely to approach the potential client, set a higher price and be less likely to have her price accepted. This is consistent with what we observe when comparing Indians and Bangladeshis. Thus our survey and transactions data are consistent. The sex workers tend to discriminate against whites and in favor of Bangladeshis based on their perceived willingness to pay but against Indians based on animus. These results are robust to including sex worker fixed effects in the analysis of the transactions data.

\section{The Commercial Sex Industry in Singapore}

There is considerable demand for prostitution among locals. ${ }^{2}$ In many professions, women in Singapore have outperformed men, and few are willing to marry below

\footnotetext{
${ }^{2}$ Almost half of the sex clients in Indonesia's Riau region, an island proximate to Singapore, are from Singapore (Williams, Lyons, and Ford, 2012).
} 
their education and economic status. Around 2005, there were headlines about the existence of 300,000 white-collar workers who could not find wives. At the same time, the roughly 1.2 million foreign workers comprise one third of the Singaporean workforce (Ministry of Manpower, Singapore, 2012). Ten percent of foreign workers are professional, managers, executives or technicians, while $70^{3}$ percent are low- and semi-skilled workers, including many men in the construction and manufacturing sectors. In addition, in 2011 Singapore attracted 13.2 million tourists (Singapore Tourism Board, 2012), many of whom seek sexual services. Consequently, the client base for prostitution is comprised of many different ethnicities.

Prostitution in Singapore dates to the 1800s when Singapore was a British colony (Warren, 1993). In the late 1990s, the authorities issued special licenses for the operation of "legal" brothels, over 100 of which remain. ${ }^{4}$ There is also an illegal market with three main segments: the even-numbered lanes of Geylang (the lowend), the renowned Orchard Tower Bars (the mid-tier), and nightclubs (the highend). Sex workers in Geylang and Orchard Tower Bars are mostly full-time with no other source of income. In contrast, many women working in the nightclubs are hired legally by the clubs as dancers, singers or hostesses and make money as sex workers on a part-time basis. The illegal sex workers come primarily from China, Thailand, Vietnam and the Philippines on short-term visitor passes (Agence France Press, 2008). They visit Singapore from time to time seeking lucrative earning opportunities and marriage opportunities with Singaporean and western men.

We focus on Geylang, the low end and largest section of the market, but some of our data on sex workers' beliefs and tastes also draw on interviews with sex workers at Orchard Tower and the nightclubs. We have no data on more scattered forms of illegal prostitution such as KTVs (entertainment pubs with activities such as karaoke), massage parlors and social escorts. Sex workers from these venues represent a relatively small portion of the total sex worker population in Singapore.

Sex workers in Geylang are located on the even numbered lorong (lanes). Our qualitative interviews suggest that each lorong is controlled by one or more pimps who oversee the business, protect the women from abnormal clients and arrest in the event of a police raid, and provide accommodation. Tourist visas enable sex workers to re-enter Singapore frequently. When a sex worker travels to Singapore, the costs are usually borne by the parties who manage her trip and work. In return, she provides the first 60 services for free and pays $\$ \$ 10 /$ day and 30-40 percent of her subsequent earnings to the pimp. Our survey results are consistent with these

\footnotetext{
${ }^{3}$ These statistics exclude foreign domestic workers. (Ministry of Manpower, Singapore)

${ }^{4}$ This license is not a license for prostitution per se, but a special business license which allows brothel owners to operate the brothel under police authority
} 
numbers for those sex workers who report having a pimp. However, even among those answering the question, roughly half of the sex workers reported not having a pimp. Our qualitative interviews suggest that even sex workers who do not have a pimp have some form of male protection. We expect that the distinction is related to the nature of the "contractual" relation. Whether the sex worker is employed by a pimp or vice versa, pimps are typically distant from the negotiation since the penalties for pimping are quite severe. Therefore, pimps are not in a position to control prices, and as we will see, there is considerable within sex worker variation in price even controlling for detailed services.

Geylang is a favorite destination for less wealthy clients seeking cheap sexual services. Chinese, Thai and Vietnamese sex workers dominate. The plentiful supply of Chinese women makes Geylang the preferred choice for Chinese clients who desire a "girlfriend" experience with the sex worker. It is also a particularly attractive venue for elderly single men who desire companionship. Clients are mostly Singaporean, Bangladeshi, white and Indian. Bangladeshi construction workers, in particular, are frequent visitors to the Geylang red light district, representing a sizable demand for affordable sexual services.

The Geylang market is highly competitive. ${ }^{5}$ Prostitution activities are concentrated in a small zone within which large numbers of nearly homogeneous sex workers solicit on the streets. There is little differentiation in the services offered. Differences in sex workers' characteristics, such as beauty, may make one more desirable than the other. Nevertheless, our interviews with clients indicate that they are nearly perfect substitutes in the clients' eyes. ${ }^{6}$ We also note that this tendency is reinforced by the segmentation of the market. More attractive sex workers are likely to be at Orchard Towers. Older sex workers frequent Petain Road, a smaller red light area. We will further address this issue by controlling for sex worker fixed effects.

At the same time, clients face no legal risk from patronizing sex workers, and the reputational risk is minimal because Geylang is a popular tourist and dining destination. Most importantly, during "normal business hours" (roughly late afternoon

\footnotetext{
${ }^{5}$ According to police estimates, there are approximately 2,000 street sex workers in Geylang, Desker Road and nearby Petain Road and Keong Saik Road in Singapore on any given night (Chong Chee Kin, 2005). It is a safe bet that more than 1,200 street sex workers are active in Geylang on a typical night as Geylang is the largest red light district. There are roughly 11,500 linear feet of road in the Geylang red light district. Allowing for both sides of the road, this suggests an average of about 30 feet between sex workers on a single side of the road. Of course, the sex workers do not distribute themselves evenly or even randomly. So a novice might take a few minutes to find a group of sex workers but would be likely to find several in close proximity once he does. Newspaper reports by The Electric New Paper (2008) and Othman and Yusof (2014) also indicate a large sex worker population in Geylang in recent years

${ }^{6}$ Levitt and Dubner (2009) makes this claim in SuperFreakeconomics. Our interviews with the clients reveal the same fact.
} 
until early morning), clients can easily locate a match within 2-5 minutes due to the high density of sex workers on the street.

Because the initial exchange between sex workers and clients takes place on a public street, flirting and negotiation time are relatively short. Based on our survey, almost 40 percent of negotiations are reported as having taken zero minutes, and the median is three minutes. The service rate ranges from $\mathrm{S} \$ 27$ to $\mathrm{S} \$ 250$ with a median of $\mathrm{S} \$ 60$ and mean of $\mathrm{S} \$ 70 .^{7}$ Over 92 percent of sexual services took place in motels and hotels, with the remainder primarily at the client's residence. A full-time sex worker will return to her original venue immediately after finishing with a client. Any costs, such as taxi fare and hotel room charges are usually borne by clients.

\section{Theory Model}

Customers, $c$, search for sex workers, $i$. And sex workers search for customers. When a potential client and sex worker meet, the sex worker must decide whether to approach the client. She offers a price, and the potential client decides whether to accept the offer.

We assume that the client's utility from a successful match with a sex worker is given by

$$
u_{i c}=v_{c}-w_{i c}+\varphi_{i c}
$$

where $v$ is the value he places on the service, $w$ is the wage paid to the sex worker and $\varphi$ is match-specific quality (i.e. how much this customer likes this sex worker). We will assume that $v$ is public knowledge but only the client observes $\varphi$. It simplifies analysis to assume that $\varphi_{i c}$ is entirely idiosyncratic.

\subsection{The Client's Problem}

The client searches for a sex worker sequentially without recall. We assume that he meets one sex worker each period, but this assumption could easily be relaxed by reinterpreting the discount factor. When the client meets a sex worker, he observes his value of $\varphi$ from the match and learns her wage demand. We write the cumulative distribution of $\varphi-w$ as $G$. In equilibrium with identical sex workers, all sex workers will choose the same $w$ so that $G$ will just be the distribution of $\varphi$. However, at this stage we allow $w$ to vary since we have not yet established that its distribution is degenerate. In addition, this establishes that the results for clients hold even when sex workers charge different prices.

\footnotetext{
${ }^{7}$ At the time of writing, a Singapore dollar is worth eighty U.S. cents.
} 
As is standard in such problems, the client chooses a reservation utility, $u^{*}$, to maximize his expected utility from the search process, which is given by

$$
U\left[u^{*}\right]=\left(1-G\left[u^{*}-v\right]\right) v+\int_{u^{*}-v} x d G(x)+\delta G\left[u^{*}-v\right] U
$$

The first term is the standard value of the service multiplied by the probability that $\varphi-w$ is sufficiently high that the client accepts the sex worker's offer. The second term is the added surplus from good matches that are accepted. The last term is the discounted value of returning to search multiplied by the probability of this event. Rearranging terms and dropping the arguments of the $G$ function gives:

$$
U=\frac{(1-G) v+\int_{u^{*}-v} x d G(x)}{1-\delta G} .
$$

Optimality requires that the client be indifferent between accepting his reservation utility and searching again next period so that

$$
u^{*}=\delta U
$$

or

$$
-u^{*}(1-\delta G)+\delta\left((1-G) v+\int_{u^{*}-v} x d G(x)\right)=0 .
$$

Lemma 1. $\frac{\partial u^{*}}{\partial v}<1$.

Proof. By the implicit function theorem

$$
\frac{\partial u^{*}}{\partial v}=\frac{\delta(1-G)}{(1-\delta G)}<1
$$

Lemma 2. If each sex worker increases her wage demand by $d w, d u^{*} / d w>-1$.

Proof. $v_{i}$ and $-w_{i c}$ enter (equation 1 ) symmetrically. An equal increase in all $w_{i c}$ is identical to an equal and opposite change in $v_{i}$.

Remark 1. If sex workers change their prices by different amounts, $d u^{*}$ must be greater than the additive inverse of the largest price increase. If sex workers have mass, $u^{*}$ is decreasing in each sex worker's pricing decision.

\subsection{The Sex Worker's Problem}

Each time the sex worker meets a potential client, she makes him a take-it-or-leaveit offer. If the offer is accepted, she receives $w$, pays an effort or psychic cost of $c$, 
which may depend on the client, and returns to work after a delay reflecting the time it takes to provide the service. If the offer is declined, she returns to work after a delay caused by bargaining. ${ }^{8}$ We denote the value of a vacancy by $\pi_{v}$. Note that $\pi_{v}$ deviates from $\pi$ both because she will generally face a delay before meeting a new client and because the current client may be more or less desirable than average. Faced with a client, she chooses $w$ to maximize her expected profit which is given by

$$
\pi=\left(1-F\left[u^{*}-v+w\right]\right)\left(w-c+\gamma \pi_{v}\right)+F\left[u^{*}-v+w\right] \lambda \pi_{v}
$$

where $F$ is the cumulative distribution of $\varphi$. We assume that $F$ has the increasing hazard property. Note that $\gamma<\lambda$ since she is out of the market longer providing a service than if the offer is rejected.

The sex worker will choose not to approach the client if

$$
\max _{w}\left(1-F\left[u^{*}-v+w\right]\right)\left(w-c+\gamma \pi_{v}\right)+F\left[u^{*}-v+w\right] \lambda \pi_{v}<\pi_{v}
$$

The first-order condition for the sex worker's problem is

$$
-F^{\prime}\left(w-c+(\gamma-\lambda) \pi_{v}\right)+(1-F)=0
$$

where we have again dropped the argument of the distribution function for ease of presentation.

Lemma 3. $0>\frac{\partial w}{\partial u^{*}}=-\frac{F^{\prime}+\frac{(1-F)}{F^{\prime}} F^{\prime \prime}}{F^{\prime \prime} \frac{(1-F)}{F^{\prime}}+2 F^{\prime}}=-\frac{\partial w}{\partial v}>-1$

Proof. By the implicit function theorem

$$
\frac{d w}{d u^{*}}=-\frac{\left(F^{\prime \prime}+F^{\prime}\left(w-c+(\gamma-\lambda) \pi_{v}\right)\right)}{\left(F^{\prime \prime}\left(w-c+(\gamma-\lambda) \pi_{v}\right)+2 F^{\prime}\right)} .
$$

Substituting using (equation 8) proves the first part of the lemma. Proof of the second part is identical. The inequalities follow from the assumption of an increasing hazard function and inspection.

Lemma $4.1>\partial w / \partial c>0$

\footnotetext{
${ }^{8}$ It might appear that there is a contradiction between assuming take-it-or-leave it offers and including a bargaining delay in the model. However, sex workers must first ascertain the services in which the potential client is interested before quoting a price. Therefore even immediately rejected offers take time.
} 
Proof. By the implicit function theorem

$$
\begin{aligned}
\frac{\partial w}{\partial c} & =-\frac{F^{\prime}}{-F^{\prime \prime}\left(w-c+(\gamma-\lambda) \pi_{v}\right)-2 F^{\prime}} \\
& =\frac{\left(F^{\prime}\right)^{2}}{F^{\prime \prime}(1-F)+2\left(F^{\prime}\right)^{2}} .
\end{aligned}
$$

The inequalities follow from the increasing hazard assumption.

\subsection{Comparative Statics}

We are now in a position to prove the main theoretical result of the paper.

Theorem 1. An increase in $v$

1. Lowers $u^{*}-v$ and thus increases the acceptance rate

2. Raises $w$

3. Raises $\pi$.

Proof. Lemma 1 establishes part 1 in the absence of a wage increase by sex workers (lemma 3), which induces a decrease in $u^{*}$ (lemma 2). However, each of these responses reinforces the effect. Therefore to prove parts 1 and 2, we need only show that the system of equations is stable which follows from the fact that $\partial w / \partial u^{*}>-1$ (lemma 3) and $\partial u^{*} / \partial w>-1$ (lemma 2). The third part of the theorem follows from the first two parts.

Theorem 2. An increase in $c$ for all sex workers raises $w$, lowers the acceptance rate and lowers $\pi$.

Proof. From lemma 4, absent other changes, $\partial w / \partial c>0$. Since $-1<\partial u^{*} / \partial w<0$ (lemma 2) and $\partial w / \partial u^{*}<0$ (lemma 3 ), additional adjustments reinforce this result, but lemma 2 ensures that the acceptance rate cannot rise. Suppose that $\pi$ increased. Since the acceptance rate declines, we must have that $d w>d c$. But by (equation 8) and the increasing hazard assumption, this can be an equilibrium only if the acceptance rate is higher, a contradiction.

It has been convenient to assume that all sex workers are identical except for an idiosyncratic match-specific component. However, none of the lemmas depend on this assumption. Proof of the theorems would be more complicated, and it does not appear that allowing for such heterogeneity would add much insight. Similarly, although take-it-or-leave-it bargaining gives rise to a simple solution, most models 
of bargaining under one-sided asymmetric information imply that those who value the item more do worse in bargaining.

If some, but not all, sex workers were prejudiced against a given group, the prejudiced sex workers would raise the price they charge members of that group. As noted in remark 1, this will lower the reservation utility of clients subject to discrimination. By lemma 3, this will, in turn, cause unprejudiced sex workers to also charge higher prices, but not sufficiently to reduce the probability of acceptance and profit to the level that would prevail in the absence of prejudiced sex workers. ${ }^{9}$ In essence, clients who face discrimination have a higher willingness to pay and unprejudiced sex workers subject them to discrimination in the same way that they do other clients with a perceived high willingness to pay.

For the most part, we do not pursue this prediction because we have very few transactions between Indians, the group against whom we suspect there is taste discrimination, and sex workers who report not being prejudiced against them. Moreover, unless Indians could tell whether they were bargaining with a prejudiced or unprejudiced sex worker, we would have two-sided imperfect information which creates significant theoretical problems for bargaining models. Nevertheless, we briefly discuss some suggestive evidence based on the behavior of Singaporean Indian sex workers.

\subsection{Empirical Predictions}

Step 1. Decision to Approach

Sex workers will be more likely to approach ethnicities whom they associate with higher willingness to pay and less likely to approach those for whom they express dislike.

\section{Step 2. Price Setting}

Conditional on approaching the client, sex workers will ask a higher price of both those ethnicities whom they associate with a higher willingness to pay and those for whom they express dislike.

Step 3 Client's reaction to the price offer

Conditional on the sex worker approaching, members of groups whom sex workers associate with higher willingness to pay will be more likely to accept. Members of groups subject to taste discrimination will be less likely to accept.

\footnotetext{
${ }^{9}$ This is similar to the result in Black (1995).
} 


\section{Survey and Data}

\subsection{Survey Design and Data Collection}

The survey, conducted under the direction of the first author, collected information about the sex worker and her recent business transactions. For each worker we have basic demographic information, attitudinal information regarding clients of different ethnicities and her report regarding the factors that influence her decision to approach a client and the price to ask. In addition, enumerators rated the interviewees on aspects such as beauty, physical figure and English skills as they believed clients would judge them. Rating workers from the client's point of view is a common practice in surveys of sex workers. We also collected information regarding the most recent 4 to 7 transactions (who initiated the contact, initial price, whether agreement was reached, final price, services provided and characteristics of the client such as ethnicity, attractiveness, and quality of dress).

The questionnaire provided a general structure to the interview. The combination of the nature of the subject and frequent language difficulties meant that enumerators found it more effective to use the questionnaire to guide the conversation while maintaining the freedom to change the order of questions and to rephrase questions in order to make sure the sex worker understood what was being asked.

To gain access to the sex workers, we hired one female and three male enumerators, all roughly forty years old, who had prior experience in this market and were friendly with sex workers and/or pimps. ${ }^{10}$ Their personal connections enabled us to conduct phone and personal interviews with the sex workers, pimps and regular patrons and thereby acquire much of the institutional background that informs this study and allowed us to develop and refine the survey instrument before taking it into the field.

It is not feasible to fully randomize the sample in this market since due to the underground nature of the business, we lack complete information on the composition of the target population and its geographic distribution. In addition, some sex workers refused to be interviewed or were forbidden from doing so by their pimps although this latter case could sometimes be addressed through a small gift or invitation to have a drink. The enumerators estimate a refusal rate of about $30 \%{ }^{11}$

\footnotetext{
${ }^{10}$ One was the boyfriend of a female pimp in Orchard Tower; the second worked in a non-sex worker capacity at a night club. The third and fourth were a close friend of a Geylang pimp and that pimp.

${ }^{11}$ It is not possible to have a precise refusal rate because in some settings the objections of a pimp would require the enumerator to withdraw from a location without information on the number of sex workers who would have been selected for the sample.
} 
Strikingly, experienced sex workers were more open to our interview requests. Finally, less attractive sex workers have longer unemployment periods during each shift and are more tempted by the gift voucher we offer.

Nonetheless, we compensated for this limited control by visiting different lanes at different times and on different days of the week. This strategy ensures a moderately randomized sample since the locations at which we sought interviews were random. Furthermore, sex workers spend a fair amount of their work day waiting for a customer so that we had a good chance of finding a sex worker if she was usually located at the spot and time we selected.

We study only heterosexual transactions where the women are the sellers and the men are the buyers. The enumerators read a letter of consent to gain the sex workers' understanding and consent before starting the interviews. Each interview took about 30-45 minutes. The enumerator was paid $\$ \$ 15$ for each survey, and each interviewee received a gift voucher of $\mathrm{S} \$ 10$ to compensate for her time. Sometimes the sex workers agreed to take the survey as a favor to our enumerators and did not ask for a monetary reward. In those cases, the enumerators invited them for a simple meal and conducted the interview either during the meal or on a separate occasion.

The first author scrutinized each completed survey carefully to weed out major mistakes, especially in the early stages. Reviewing the survey right after submission allowed us to correct errors immediately before the enumerators forgot the information. Data-entering personnel recorded any unconventional answers following the rules we formulated and made notes on a separate sheet for the changes for each data point. For example, many of the sex workers could not recall the exact amount of their earnings and their clients' ages. Thus, the data entry personnel calculated the average using the range provided and made a note of these changes. About thirty of the earliest surveys were excluded because of clear communication failures. About twenty interviews were interrupted by events such as police patrols and had to be discarded because they could not be completed.

Business in the sex market is seasonal. June (Great Singapore Sale), September (Formula One Grand Prix) and December (Holiday season), when Singapore faces a surge of tourists, are the peak months. January and February have both less supply and demand due to the Chinese New Year. The data were deliberately collected during the low season for tourists, late February to August, excluding the period of the Great Singapore Sale. We were somewhat concerned that prices might rise during the high tourist season. This could increase the proportion of inexperienced sex workers in the market and might also lead some locals to significantly reduce 
their demand. Nevertheless, there is a significant tourist component in the client base at all times of the year.

\subsection{Data Description}

The sample consists of 176 street sex workers from Geylang and 814 transactions. Three observations were dropped because client's ethnicity was not recorded. There were 678 transactions where the sex worker made the first offer, 130 transactions where the clients initiated the price and 6 where this was not determined. We focus on the first set of transactions although we use all transactions in some specifications.

Transactions are limited to cases in which there was real interaction between the sex worker and the potential client. They do not include the common event where the sex worker tries to attract a client and is rebuffed with no expression of interest. Consequently our measure of whether the sex worker approached the client corresponds only imperfectly to our theoretical measure. If a potential client was near to a sex worker but neither party approached the other, we are unaware of the event. We only have information on who initiated the interaction if one party approached the other, and there was sufficient engagement that price was discussed. The validity of our approach is predicated on the assumption that the sex worker's tendency to approach a client of a given type is associated with the probability that the sex worker rather than the client initiated the interaction.

\subsubsection{Sex Workers' Characteristics}

Table 1 reports the characteristics of the sex workers in the full sample. About onethird of the sex workers come from each of China and Thailand. The remainder come from Vietnam and Indonesia except for a small group of Singaporean Indians. As expected, they have low educational attainment. Fully 72 percent have completed no more than primary education, including 21 percent who are illiterate. Less than 10 percent of the sample have been educated through high school. The average age of the sex workers is 26, with the youngest aged 18 and the oldest aged 39. Two-thirds of the sex workers in the sample are single and only 11 percent are currently married while 23 percent have at least one child. Over half the sample had at least 2 years' experience as a sex worker prior to working in Singapore. The average respondent had been working in Singapore for about 2 years.

Geylang street sex workers report that they work 6-7 days a week, averaging 9 hours on weekdays and 11 hours on weekend days. They on average have only about 4 customers per day, suggesting that much of their day involves waiting for clients. 
They earn an average of somewhat more than $\$ \$ 3,200 /$ month from sex, substantially more than they earn at home. About one-third of the sex workers report income from sources other than sex. ${ }^{12}$

Despite our understanding that Geylang sex workers are controlled by pimps, over half of the sex workers who answered the question and one-third of all sex workers said that they did not have a pimp. Interestingly, the sex workers who report having pimps also report less experience in Singapore, in the sense of stochastic dominance. This is true even if we drop the Singapore Indian sex workers, none of whom reports having a pimp. Of the small number who report the pimp share, the mean is within the 30-40 percent range, which is consistent with the share reported to us in conversations with insiders.

\subsubsection{Client Characteristics}

Chinese, mostly Singaporean but including some Malaysian Chinese, comprise the largest ethnic group among the clients, followed by Bangladeshis, whites and Indians. There are smaller numbers of Malays, Japanese and Koreans, and Middle Easterners and a handful of black Americans. Except for Indians and Bangladeshis who comprise the vast majority of the clients of the Indian sex workers, there is surprisingly little matching between the ethnicity of clients and sex workers (see table 2). In particular, Chinese clients are no more likely to frequent Chinese sex workers than are other clients.

Clients' ages, as estimated by the sex workers, range from 20 to 60 and average about 37. About 30 percent of customers are tourists and about 20 percent are repeat customers. There is no statistically significant difference in these proportions by sex worker country of origin.

On a scale of 1 to 5 where 1 is dress very badly and 5 is dress very well, sex workers tend to think that their clients dress rather poorly (mean equals 2.4) and on a similar scale find their customers unattractive (mean equals 2.0). ${ }^{13}$

\subsubsection{Sex Workers' Views of Clients}

The sex workers were asked to rate different ethnicities on a scale of 1 (dislike) to 5 (like very much) with 3 being "like." They consistently give high ratings to Chinese (4.2) and white (3.9) clients (see the top row of table 3). ${ }^{14}$ In contrast,

\footnotetext{
${ }^{12}$ Our understanding is that these are primarily payments for nonsexual companionship.

${ }^{13}$ These means exclude sex workers who claim not to notice dress/attractiveness.

${ }^{14}$ Although not shown in the table, Koreans/Japanese receive ratings similar to those of Caucasians while Malaysians fall between Bangladeshis and Indians.
} 
the Bangladeshi and Indian clients earn average ratings of 3.1 and 2.1. ${ }^{15}$ Although sample sizes are small, this distinction does not appear to be greatly affected by the sex worker's country of origin except that Singaporean Indian sex workers assign higher ratings to Indians and Bangladeshis. ${ }^{16}$

To understand the sex worker's preferences, we rely on informal conversation with sex workers and pimps and a nonrandom sample of 66 sex workers from all three illegal market segments whom we asked "Given the same price and equally attractive clients, do you prefer ethnicity X or ethnicity Y and why?" and, for cases where bargaining failed, we inquired about the reason. The attraction of Chinese clients is that they are more likely to be returning customers. White, Korean and Japanese clients are willing to pay a higher price. In contrast, Indians are less popular among sex workers mainly because of their dark skin tone and lower expected wealth, and to a lesser extent because they are perceived as more demanding/rough and bargain a lot. Surprisingly, since we would expect few sex workers to be able to distinguish between the two, many sex workers compare Bangladeshis favorably to Indians. Feedback from sex workers and pimps suggests that they uniformly describe men with lighter skin tone as Bangladeshi. ${ }^{17}$ The sex workers often maintained that Indians take longer to service but are unwilling to pay a commensurately higher price and bargain harder. Some interviewees justify their distaste towards Indians by claiming that Indian men have a higher probability of being sexually violent. While we cannot preclude the possibility that the sex workers' dislike for Indians is based on a rational assessment of the risk of violence or more demanding sex, the qualitative interviews point us towards prejudice. The implications of our model do not depend on whether dislike is justified or unjustified.

The sex workers reported that ethnicity was an important factor in determining which potential customers to approach and the initial price to set. In addition, the value of previous tips and gifts (for repeat customers) and the client's appearance were also listed as important factors.

\footnotetext{
${ }^{15}$ For reasons we have been unable to ascertain, the question about Bangladeshis was not asked of a significant minority of the sex workers.

${ }^{16}$ These discriminatory attitudes appear to be mutual. Interviews with insiders reveal dark skin sex workers like Singaporean Indians and Indonesians are least popular in the market, especially among the light skin clients

${ }^{17}$ Indian and Bangladeshi clients in Geylang are mostly construction workers. Among this group, the association between skin tone and nationality appears largely to be empirically valid.
} 


\subsubsection{Transaction Characteristics}

The average unit price for sex is $\mathrm{S} \$ 70$ with lowest rate of $\mathrm{S} \$ 27$ and highest rate of $\mathrm{S} \$ 250{ }^{18}$ The average service duration is around an hour, but this is skewed by a modest number of cases where the service was for all or most of the night. The median is 45 minutes. Most of the transactions take place in either motels (70 percent) or hotels (22 percent). Only about 6 percent of the transactions occur in the client's residence. There is very high awareness of contraception among both clients and sex workers in Singapore. There is only one case in which the sex worker reported that the client had not used a condom.

Table 3 shows some transaction characteristics for the four most common client ethnicities and for all ethnicities together. In row 2 , we show the initial price offered by sex workers to their potential clients. Among these groups, whites face the highest initial price ( $\mathrm{S} \$ 91)$ and Bangladeshis the lowest $(\mathrm{S} \$ 49)$ with Chinese ( $\mathrm{S} \$ 74$ ) and Indian ( $\$$ \$67) clients falling in between. Row 3 restricts the sample to those transactions where bargaining was successful. Perhaps surprisingly, the mean initial offers are similar.

Note that while the model assumes that sex workers can make take-it-or-leave-it offers, in practice clients can and do sometimes make counter-offers. We know that in 55 percent of the cases in which the sex worker made the first offer, the transaction price equaled her initial offer while in 2 percent of the cases it was higher. Bargaining failed after a very short interval in a further 2 percent of cases.

Row 4 shows the mean contracted price. The ranking of prices is unchanged although whites receive a somewhat larger discount. These differentials are in line with or somewhat larger than those in Levitt and Dubner (2009) who report that in Chicago whites pay $\$ 9$ more per sexual service than do black customers, with prices for Hispanic customers falling in between.

Row 5 shows that sex workers make the first move almost three-quarters of the time. However, they are almost always the first mover with whites. Even though both initial prices and transactions prices are higher for Indians than for Bangladeshis, sex workers are much more likely to be the one who approaches a potential client who is Bangladeshi (67 percent) than one who is Indian (43 percent). At the same time, we see in row 6 that while bargaining almost never fails with whites and rarely fails with Chinese potential clients, there are significant failure rates with both Bangladeshis (24 percent) and Indians (26 percent).

\footnotetext{
${ }^{18}$ The rate in legal brothels in Geylang is fixed at $\mathbf{\$} \$ 50$ per 20 minutes, half of which goes to brothel owner. It is typical for a legal brothel sex worker to serve 10-20 customers a day, as the average duration for each service is about 20 minutes.
} 
These results are largely consistent with our theoretical model and qualitative evidence. Sex workers view whites as willing to pay high prices. They therefore are more likely to approach them, ask for a higher price and are more likely to reach a deal, while the opposite is true for Bangladeshis. The results for Indians compared with Bangladeshis are consistent with our findings of animosity towards Indians. On the other hand, Indians are charged lower prices than are Chinese customers, suggesting that sex workers also believe they have a lower willingness to pay than Chinese or white customers. With respect to the claim by some sex workers that their dislike of Indian clients is objective rather than subjective, we see that contrary to claims that some of them make, Indians do not have long service duration, do not get an unusually large price reduction from the initial offer (suggesting that they do not bargain harder) and do not have an unusually high rate of demand for anal sex, our only proxy for roughness. Their average bargaining time (not shown) is shorter than the average for all other ethnicities except Chinese clients whose three-second shorter average bargaining time relative to Indians is more than entirely explained by shorter bargaining with Chinese sex workers. While we can never completely rule out objective factors, these findings support the clear inference from the qualitative interviews that it is skin tone rather than objective factors that drives many sex workers' dislike of Indians.

Of course, these differences could reflect other factors. The next rows show characteristics of the transactions that actually took place. Almost all clients request vaginal sex. The real variation is in demand for oral and anal sex, both of which command a price premium. Chinese and white clients are most likely to have oral sex. This is somewhat less common among Indians and much less common among Bangladeshis. On the other hand, anal sex is most common with whites and less common with other ethnicities. Median duration of service is highest among whites and lowest among Bangladeshis and Indians ${ }^{19}$ which may suggest that the higher prices paid by whites and lower prices paid by Bangladeshis reflect a compensating differential for longer service. Except for Indians, the average prices per minute do not vary much by ethnicity. However, we will see that the marginal cost of duration is below the average so that duration does not account for the differentials.

It is not clear whether it should be advantageous to engage in "sweet talk." ${ }^{20} \mathrm{On}$ the one hand, sex workers may prefer clients who tell them they are beautiful. On

\footnotetext{
${ }^{19} \mathrm{We}$ use medians instead of means to minimize the effect of a small number of very lengthy exchanges, some of which lasted the entire night.

${ }^{20}$ Sweet talk captures the flirtation between the sex worker and the client. We control for this factor because the sex workers indicated in the survey that their decisions on price may be influenced by the client's sweet talk.
} 
the other, such cheap talk may be perceived as an indication of higher willingness to pay. The mean of this categorical variable (from 1 to 5 ) is highest for whites and lowest for Bangladeshis.

\section{Identification}

\subsection{Estimation Equations}

Since our model has the sex worker making a take-it-or-leave-it offer, our principal specification restricts the sample to cases where the sex workers initiate price. Only one out of seven transactions involved the client suggesting the initial price. We do, however, use all transactions as a robustness check.

We estimate the following equations:

$$
\begin{gathered}
\text { Move }_{i j}^{*}=\Sigma_{j} \beta_{1 j} E_{j}+X_{j} B_{1}+\Sigma \delta_{1 i} W_{i}+Z_{i g}^{1} \Gamma_{1}+\varepsilon_{1 i j} \\
\ln \text { Price }_{i j}=\Sigma_{j} \beta_{2 j} E_{j}+X_{j} B_{2}+\Sigma \delta_{2 i} W_{i}+Z_{i g}^{2} \Gamma_{3}+\varepsilon_{2 i j} \\
\text { Fail }_{i j}^{*}=\Sigma_{j} \beta_{3 j} E_{j}+X_{j} B_{3}+\Sigma \delta_{3 i} W_{i}+Z_{i g}^{3} \Gamma_{3}+\varepsilon_{3 i j}
\end{gathered}
$$

where $i$ is the sex worker and $j$ is the client.

The dependent variable $M o v e^{*}$ is a latent variable capturing the tendency of the sex worker to approach the client. If and only if the latent variable is positive, we observe that the sex worker approached the client rather than vice versa. This is an imperfect proxy for whether the sex worker finds it worthwhile to approach. There are undoubtedly occasions where the client approached first where the sex worker's expected surplus was positive and many occasions on which we do not observe the sex worker's failure to approach because the potential client also chose not to approach. Our principal estimation method for (9) is fixed-effects logit. If price discrimination is driven by perceived willingness to pay, we should see that the ethnicities for whom the initial price is higher are also those that the sex workers are more likely to approach.

The variable $\ln$ Price is the natural logarithm of the initial price offered by the sex worker. Equation (10) is estimated by ordinary least squares with sex worker fixed effects. As a robustness check, we also estimate versions of the equation in which the transaction price is used in lieu of the initial price. Of course, we do not observe the transaction price when the bargaining fails. Consequently, these estimates must be used with caution.

Fail $^{*}$ is the latent tendency for negotiation to fail. We estimate (11)using fixed- 
effects logit. However, since failure to reach an agreement is relatively rare, this approach results in the loss of a large number of observations. Therefore, we also rely on standard logit and control for sex worker characteristics ${ }^{21}$ while clustering on sex worker.

The explanatory variables in the equations are $E_{j}$, dummy variables for the ethnicity of the client (Chinese men are the base group), $X$, a set of client characteristics, which includes the client's age, whether he is a regular customer and whether he is a tourist and the ratings the sex worker gives to the client based on his outfit, attractiveness and "sweet talk," except that this last variable is excluded from the decision to approach, $W_{i}$, sex worker fixed effects, and $Z$, a set of match-specific variables that varies among the equations because of different information available.

Our theory distinguishes three cases although we recognize that hybrids are possible:

Case 1. Statistical discrimination + No/Weak Taste Discrimination:

$\beta_{1}>0, \beta_{2}>0, \beta_{3}<0$

If, for example, as suggested by our qualitative interviews, sex workers believe that whites have a higher willingness to pay than the Chinese and if there is no or only very weak taste-based discrimination, we expect, ceteris paribus, the sex workers to more actively approach whites, suggest a higher price and to be more likely to successfully conclude negotiations with them. Of course, a group like the Bangladeshis whom we anticipate benefit from statistical discrimination based on willingness to pay should have coefficients with the opposite signs.

Case 2. Taste Discrimination + No/Weak Statistical discrimination:

$\beta_{1}<0, \beta_{2}>0, \beta_{3}>0$

If, as suggested by our qualitative interviews, sex workers tend to dislike Indians, and, if statistical discrimination based on willingness to pay is of little or no importance, sex workers should be less likely to approach Indians, suggest a higher initial price and be less likely to reach an agreement with them.

Case 3. No Statistical discrimination + No Taste Discrimination:

$\beta_{1}=\beta_{2}=\beta_{3}=0$

This is a trivial case. When there is no discrimination, we should observe equal treatment towards clients of all ethnicities.

Finally, we note that other combinations are either inconsistent with our model or are possible only if there are multiple sources of discrimination.

\footnotetext{
${ }^{21}$ The sex worker's country of origin, age, years of experience, education, marital status, beauty and English skills.
} 


\section{Empirical Results}

\subsection{Price Discrimination}

We saw in table 3 that the raw price differences among ethnic groups were consistent with our qualitative data on sex workers' beliefs. However, these differentials might simply reflect matching of more attractive and therefore higher price sex workers to wealthier clients. Our qualitative interviews do not support this interpretation; clients claim that sex workers are highly substitutable in their eyes. While richer clients favor more beautiful sex workers and can afford them, our interviews suggest that they are (almost) equally happy to buy services from less attractive workers. And those who are willing to pay more for higher class sex workers generally frequent Orchard Towers or the night clubs.

Nevertheless, to determine whether the raw price differences merely reflect sorting, we include sex worker fixed-effects in the price equation. In addition we control for client's age (as estimated by the sex worker) and its square, and dummy variables for whether the client is a repeat customer, a tourist, rated above the median in attractiveness, rated above the median in quality of dress, rated above the median in "sweet talk" and indicators for each of these variables being missing.

The first column of table 4 shows the results from this estimation. Relative to the base group (Chinese), the same sex worker suggests an initial price to whites with an 11 percent (10 log points) premium and gives Bangladeshis a 13 percent discount on the initial price offer, thus asking whites for almost 30 percent more than she asks from Bangladeshis. The point estimate suggests that our small sample of black Americans is asked the highest premium (not shown), but this estimate is very imprecise. The initial price asked of Indians is similar to that asked of Chinese prospects.

Although we have not focused on tourists as a group, we would not be surprised if they had higher willingness to pay. We observe that the initial price they face is 15 percent higher than locals (not shown). Being well-dressed and older raise the asking price. The former is presumably an indicator of willingness to pay. The latter could reflect presumed financial status or tastes, but the fact that attractiveness of the client does not affect the initial price points us towards the former. Telling the sex worker she is beautiful ("sweet talk") also raises the asking price. Finally, regular clients do not seem to be charged a premium or receive a discount relative to other locals.

Column 2 repeats the exercise but drops all observations with missing data on client characteristics and the corresponding dummy variables. The estimates are 
broadly similar to those in the first column but generally suggest somewhat larger ethnicity effects. ${ }^{22}$

Column 3 adds dummy variables for eight combinations of sex acts. In principle, there are fifteen possible combinations. In practice we observe only eight in our data. The excluded category is "sex acts unknown" which applies to virtually all of the cases where bargaining fails. The sex acts over which the parties were bargaining are reported in only four cases where sex did not take place. Note also that the services the client is requesting may not be known when the sex worker initiates price. There were five transactions in which the final price exceeded the sex worker's initial offer.

Despite this limitation, we find highly significant effects of the transacted sex acts on the initial price. However, the sex acts are not strongly correlated with ethnicity, and therefore, their inclusion does not greatly alter the ethnic differentials.

In the fourth column, we control for where the sexual activity took place. This de facto limits the sample to completed transactions and greatly reduces the sample. Controlling for duration (column 5) further reduces the sample. Nevertheless, we view this specification as important because our qualitative interviews revealed that some sex workers believe that Indians require longer service. In fact, the estimate for Indians remains almost unchanged. We continue to find robust evidence of a white premium and a Bangladeshi discount.

Finally, in column 6 we include all encounters regardless of who made the first offer. Again the results are robust to the change of sample because white clients offer higher initial prices and Bangladeshi clients offer lower initial prices, consistent with sex workers' beliefs. The modest drop in the coefficient on Indian reflects their tendency to offer a lower initial price.

In table 5, we examine the relation between the transaction price and ethnicity. We remind the reader that we do not observe this price when bargaining fails. Moreover, our model does not have predictions about the transaction price independent of the initial price since sex workers make take-it-or-leave it offers. Subject to these caveats, we note that bargaining does not eliminate the ethnicity differentials, which supports the rationality of the sex workers' pricing behavior. The white premium and Bangladeshi discount are similar in the corresponding columns of tables 4 and 5.

When we estimate the specification in column 5 using the sample for whom we

\footnotetext{
${ }^{22}$ We further experimented with including whether the transaction took place on a week-end and whether it took place during the day. Although the coefficient on white became smaller and statistically insignificant, the loss of additional observations due to missing variables led to a loss of statistical significance even if we left out these additional variables and simply dropped the additional missing observations.
} 
have a transaction price, there are some interesting differences (not shown). "Sweet talk" is associated with a higher initial price but a lower final price, suggesting that this is an effective negotiating strategy. The effect of service duration on the final price is still small, about 1 percent for an additional ten minutes but is substantially larger than the effect on the initial price (about 0.6 percent). If we limit ourselves to service durations of less than four hours, these numbers rise to 1.3 and 0.9 percent.

Before moving on to other outcomes, we examine the relation between initial offers and ethnicity when the client makes the first offer using the specification in column 1. Clients who make the first offer are not necessarily representative of all clients. Nevertheless, it is striking that Bangladeshis make substantially lower and white substantially higher initial offers relative to Chinese customers. Perhaps even more significantly, the offers made by Indians are lower than those of Bangladeshis. This is consistent either with Indians having a lower willingness to pay or with the claims of sex workers that Indians bargain harder. We find the latter view less compelling because when we limit the sample to the cases where the transaction was completed and the sex worker made the initial offer, both the initial and final prices for Indians were similar to those charged to Chinese clients (not shown).

Taken together, we view our price results as consistent with the view that whites have a relatively high willingness to pay, while Bangladeshis and Indians have a relatively low willingness to pay, but that in the case of Indians this low willingness to pay is largely offset by the sex workers' antipathy, with the consequence that they do not receive relatively low initial price offers.

\subsection{Who Approaches Whom?}

If our interpretation of prices in the previous subsection is correct, sex workers should be more likely to approach whites and less likely to approach Bangladeshis and Indians than they are to approach Chinese potential clients despite the fact that the prices paid by Indians and Chinese clients are similar.

Table 6 shows the relation between client characteristics and the probability that it was the sex worker who initiated the contact. We remind the reader that this is an imperfect measure of the theoretical variable which is whether the sex worker wishes to engage in negotiation. If the sex worker did not approach the client, and the client found the sex worker unattractive and did not approach her, we do not observe her failure to approach. The theoretical model does not permit the client to make the approach, but it seems that he should be more likely to do so in cases where she was not intending to approach him.

Column 1 shows the results from fixed-effects logit when, as in our main spec- 
ification, we restrict the sample to interactions in which the sex worker made the first offer. We observe that, as predicted, sex workers are more likely to approach whites (significant at the .05 level using a one-tailed test) and less likely to approach Indians (significant at any conventional level) than they are to approach Chinese clients. The point estimate for Bangladeshis is negative as predicted but falls well short of significance at conventional levels.

Unfortunately, the coefficients from fixed-effects logit are not readily interpretable. Therefore in the second column we replace the sex worker fixed effects with sex worker characteristics ${ }^{23}$ and do the estimation using ordinary logit while clustering the standard errors by sex worker. ${ }^{24}$ The results, shown in column 2 , are similar to the fixed-effects results.

Consequently, the marginal effects (shown in square brackets) from the ordinary logit estimates are likely to be a reasonable guide to the magnitude of the ethnicity effects. The point estimates suggest that sex workers are substantially more likely (21 percentage points) to approach whites, substantially less likely to approach Indians (21 percentage points) and somewhat less likely to approach Bangladeshis (8 percentage points) than they are to approach Chinese clients. Recall that overall, sex workers approach clients in 72 percent of cases.

Columns 3 and 4 repeat the exercise but include transactions in which the client initiated the price. The estimates are considerably less precise when we add these observations, but the magnitude of the estimated effects are similar to those in the main specification for whites (14 percentage points) and Bangladeshis (negative 7 percentage points), and substantially more negative (27 percentage points) for Indians.

\subsection{Failed Bargains}

So far our results are broadly consistent with the view that, relative to what they offer Chinese clients, sex workers charge a premium to whites and offer a discount to Bangladeshis based on the sex workers' perception of willingness to pay but dislike Indians and therefore do not offer them a discount even though they, too, generally exhibit a low willingness to pay. Based on this interpretation, we expect that, relative to bargaining with Chinese clients, bargaining is more likely to fail when the client

\footnotetext{
${ }^{23}$ This is figuratively but not literally true since Chamberlain's conditional logit does not involve estimation of fixed effects but rather partials them out.

${ }^{24}$ Given the small number of clients per sex worker, clustered standard errors should be treated with caution. For some parameters the clustered standard errors are lower than the conventional standard errors while the reverse is true for others. In no case is the interpretation of the ethnicity coefficients affected by this choice.
} 
is Indian or Bangladeshi and less likely to fail when the client is white.

Table 7 shows the relation between ethnicity and the probability that the bargaining fails. As in table 6, the sample in the first two columns is restricted to our main sample in which the sex worker made the first offer. Using the fixed-effects logit results shown in the first column, bargaining with both Bangladeshis and Indians is more likely to fail relative to bargaining with Chinese clients. The estimate also suggests that bargaining with whites is less likely to fail, but the coefficient falls just short of statistical significance at the .05 level even using a one-tailed test.

In order to be able to discuss the magnitude of the marginal effect, we again replace the sex worker fixed effects with sex worker characteristics. In contrast with the analysis of the decision to approach the client, the coefficient on white is sharply lower in the second column than in the first, suggesting that we should be cautious about using these estimates to calculate the marginal effect of the client being white on the probability that the bargain fails. Subject to this caveat, we find that bargaining fails with whites 14 percentage points less frequently and with Bangladeshi and Indians 20 and 18 percentage points more frequently than with Chinese customers. We note that these point estimates are very large. Bargaining fails in about 12 percent of cases in the entire sample and only in 4 percent of transactions involving the base group, Chinese customers.

When we extend the sample to transactions in which the bargaining was initiated by the client, we get similar results except that the one-tailed test is now statistically significant at the .05 level for whites. The magnitude of the estimated effect is slightly larger than in column 2 for whites (18 percentage points) and slightly smaller for Bangladeshis (17 percentage points) and Indians (16 percentage points).

\subsection{Singaporean Indian Sex Workers}

The theoretical model implies that if most sex workers engage in taste discrimination against Indians, sex workers who do not have a distaste for Indians should nevertheless charge a premium and therefore be more likely to approach them and reach an agreement. We use being a Singaporean Indian sex worker (hereafter Indian) as a proxy for not having a distaste for Indians. The sample is small; we have only 11 transactions between Indian sex workers and Indian clients. Therefore, all results should be viewed as suggestive. For this analysis we drop Bangladeshis from the sample and combine the remaining non-Indian ethnicities into a single group. We summarize the results, but do not present them in tabular form.

Indian sex workers charge Indian clients as much as other sex workers do. The coefficient in the initial price equation on the interaction between Indian sex worker 
and Indian client is actually positive but highly imprecise. However, Indian sex workers are much more likely to approach Indian clients. Using a linear probability model with the other controls, including sex worker effects, the difference is 54 percentage points and significant at the .05 level. Similarly, bargaining is less likely to fail. The difference is 32 percentage points and significant at the .1 level using a two-tailed test. ${ }^{25}$

Despite their obvious limitations, these results are broadly consistent with the theoretical model.

\section{Conclusion}

Recall that our prediction was that because sex workers believe whites have a high willingness to pay, sex workers would be more likely to approach potential clients who are white, would chose a higher initial price and would be more likely to reach an agreement. Conversely, because sex workers believe Bangladeshis have a lower willingness to pay, they are less likely to approach, set a lower initial price and are less likely to reach an agreement with Bangladeshi clients. Drawing on rich data collected by the first author on street sex workers in Singapore, we have robust evidence supporting all three predictions.

We also predicted that because there is widespread antagonism towards Indian clients, they would be charged a higher price. Prejudiced sex workers would be less likely to approach and less likely to reach an agreement with the Indian clients they approach. We find robust evidence that sex workers are less likely to approach Indians and that they are less likely to reach an agreement. We do not confirm the expectation of a higher price relative to Chinese clients; the initial prices demanded of the two ethnicities are similar, perhaps because sex workers also believe that Indian clients have a relatively low willingness to pay, a belief that would be consistent with the low offers made by Indians when they make the first offer. Consistent with our expectations, Indians pay a premium relative to Bangladeshis.

Even though this market is highly competitive with very low search costs, price discrimination is not driven from the market. Instead, we find support for Diamond's prediction that sellers have monopoly power even when search costs are very small. This, in turn, permits price discrimination based on willingness to pay. Strikingly, these modest search costs also allow the survival of taste-based discrimination, in contradiction with Becker's model.

\footnotetext{
${ }^{25}$ We confirm the results of the linear probability models with fixed-effects logit for which we use bootstrapped standard errors and calculate the 95 percent confidence interval from the distribution of the bootstrap replications.
} 
The consistency between the implications for discrimination based on sex workers' self-reported preferences and beliefs and the actual pricing and approaching decisions made by sex workers and the rate at which bargaining is concluded successfully provides strong evidence that discrimination persists even in this highly competitive market with low search costs.

Of course, it might be argued that our setting is not truly competitive. After all, sex workers are not identical. To some extent we agree. A competitive market is an ideal that, at best, will be only approximated in real-world settings. The issue is the extent to which this approximation produces relatively accurate predictions. Our view is that there are few labor markets that are likely to approximate the competitive ideal more closely than the market for sex workers in Geylang. The importance of worker heterogeneity is unlikely to be as important for a half-hour sexual encounter than it is for most employment relationships.

Thus we conclude that our findings support more recent search-theoretic models of the labor market rather than those using the traditional competitive market assumption. 


\section{References}

Agence France Press (2008): "Women trafficked to Singapore lured into prostitution," http://http://globalnation.inquirer.net/news/breakingnews/view/20080901158083/Women-trafficked-to-Singapore-lured-into-prostitution, accessed $1 / 17 / 2015$.

Arrow, K. (1973): "The Theory of Discrimination," in Discrimination in Labor Markets, ed. by O. Ahenfelter, and A. Rees, pp. 3-33. Princeton, N.J.: Princeton University Press.

Ayres, I., and P. Siegelman (1995): "Race and Gender Discrimination in Bargaining for a New Car," American Economic Review, 85(3), 304-321.

Bayer, P., M. D. Casey, F. Ferreira, and R. McMillan (2012): Price discrimination in the housing market. National Bureau of Economic Research.

Becker, G. S. (1957): The Economics of Discrimination. University of Chicago Press, 2nd edn.

Bertrand, M., and S. Mullainathan (2004): "Are Emily and Greg More Employable than Lakisha and Jamal? A Field Experiment on Labor Market Discrimination," American Economic Review, 94(4), 991-1013.

Black, D. A. (1995): "Discrimination in an Equilibrium Search Model," Journal of Labor Economics, 13(2), 309-334.

Chong Chee Kin (2005): "Are you free for tar pau?," http://unwomennc.org.sg/resources/2005/30Jul2005_Are\%20you\%20free\%20for\%20tar\%20pau.pdf.

Diamond, P. A. (1971): "A Model of Price Adjustment," Journal of Economic Theory, $3,156-168$.

Doleac, J. L., and L. C. Stein (2013): "The visible hand: race and online market outcomes," The Economic Journal, 123(572), F469-F492.

Graddy, K. (1995): "Testing for Imperfect Competition at the Fulton Fish Market," The Rand Journal of Economics, 26(1), 75-92.

Heckman, J., and P. Siegelman (1993): "The Urban Institute Audit Studies: Their Methods and Findings," in In Clear and Convincing Evidence: Measurement of Discrimination in America, ed. by Fix, and Struyk, pp. 187-258. The Urban Institute Press, Washington, D.C. 
Jacquemet, N., and C. Yannelis (2012): "Indiscriminate discrimination: a correspondence test for ethnic homophily in the Chicago Labor Market," Labour Economics, $19(6), 824-832$.

Levitt, S., and S. Dubner (2009): Super Freakeconomics, 0-06-088957-8. William Morrow, 1st edn.

List, J. A. (2004): "The Nature and Extent of Discrimination in the Marketplace: Evidence from the Field," The Quarterly Journal of Economics, 119, 49-89.

Ministry of Manpower, Singapore (2012): "Labour Force In Singapore," .

Neumark, D. (1996): "Sex Discrimination in Restaurant Hiring: An Audit Study," Quarterly Journal of Economics, 111(3), 915-41.

Othman, Z., and Z. M. Yusof (2014): "Welcome to Geylang," http://news.asiaone.com/news/singapore/welcome-geylang.

Phelps, E. S. (1972): "The Statistical Theory of Racism and Sexism," American Economic Review, 62, 659-61.

Pope, D. G., and J. R. Sydnor (2011): "What's in a Picture? Evidence of Discrimination from Prosper.com," Journal of Human Resources, 46(1), 53-92.

Singapore Tourism Board (2012): "Singapore Tourism Board Annual Report 2011/2012,"

The Electric New Paper (2008): "Is Geylang Boom Town Or Cowboy Town?," http://propertyhighlights.blogspot.com/2008_04_21_archive.html.

Warren, J. F. (1993): Ah Ku and Karayuki-san: Prostitution in Singapore (18701940). Oxford University Press.

Williams, S., L. Lyons, and M. Ford (2012): Men and Masculinities in Southeast Asiachap. Homosociality and desire: charting Chinese Singaporean sex tourists' online conversations, pp. 68-85. Routledge, Milton Park, Abingdon.

Zussman, A. (2013): "Ethnic discrimination: Lessons from the Israeli online market for used cars," The Economic Journal, 123(572), F433-F468. 
Table 1: Sex Worker's Characteristics

\begin{tabular}{lc}
\hline Variable & Mean \\
\hline Age(Sex Worker) & 26.3 \\
Experience & 2.9 \\
Experience in Singapore & 1.7 \\
Total Monthly Income(S\$) & 4371 \\
Monthly Income from Sex & 3246 \\
Days/Week Worked & 6.3 \\
Hours Worked (Weekday) & 9.0 \\
Hours Worked (Weekend) & 11.0 \\
Customers/Day & 3.9
\end{tabular}

Col \%

\begin{tabular}{lc}
\hline & Col \% \\
\hline Country & 33.5 \\
China & 33.0 \\
Thailand & 21.0 \\
Vietnam & 9.1 \\
Indonesia & 3.4 \\
SgpIndian & \\
\hline Education & 21.1 \\
Illiterate & 50.9 \\
Primary & 20.6 \\
Secondary & 5.7 \\
High School & 1.7 \\
College & \\
\hline
\end{tabular}

MaritalStatus

Single/Relationship $\quad 67.6$

Married 11.4

Divorced $\quad 19.3$

Widow $\quad 1.7$

\begin{tabular}{lc}
\hline Beauty(1=lowest; 5=highest) & \\
2 & 17.6 \\
3 & 33.5 \\
4 & 45.5 \\
5 & 3.4 \\
\hline Urban & 35.6 \\
Has Child & 22.7 \\
Has Pimp & 47.9 \\
\hline $\mathrm{N}$ & 176 \\
\hline
\end{tabular}


Table 2: Client's Characteristics by Sex Worker's Country of Origin

\begin{tabular}{lrrrrrr}
\hline & \multicolumn{5}{c}{ Sex Worker's Country of Origin } & \\
\cline { 2 - 5 } & China & Thailand & Vietnam & Indonesia & SingIndian $^{\text {a }}$ & Total \\
\hline Ethnicity & & & & & & \\
Chinese & 39.9 & 34.7 & 33.8 & 42.2 & 10.7 & 36.4 \\
Caucasian & 15.7 & 9.4 & 16.2 & 13.3 & 3.6 & 13.1 \\
Bangladeshi & 17.4 & 23.4 & 17.6 & 21.7 & 39.3 & 20.6 \\
Indian & 9.6 & 12.1 & 4.9 & 9.6 & 39.3 & 10.6 \\
Malay & 10.2 & 6.4 & 7.0 & 2.4 & 3.6 & 7.4 \\
Middle Eastern & 3.4 & 3.8 & 10.6 & 1.2 & 0.0 & 4.4 \\
JapaneseKorean & 3.4 & 9.4 & 9.2 & 8.4 & 0.0 & 6.8 \\
Black(American) & 0.3 & 0.8 & 0.7 & 1.2 & 3.6 & 0.7 \\
\hline Tourist & 26.6 & 32.3 & 30.7 & 25.3 & 42.9 & 29.5 \\
Repeat Clients & 20.5 & 13.9 & 22.5 & 21.7 & 17.9 & 18.8 \\
Age & 37.2 & 36.5 & 36.9 & 40.7 & 37.0 & 37.3 \\
Dress ${ }^{b}$ & 2.3 & 2.2 & 2.8 & 2.5 & 2.3 & 2.4 \\
Looks & 2.0 & 1.8 & 2.4 & 2.1 & 2.0 & 2.0 \\
\hline \hline
\end{tabular}

${ }^{a}$ SingIndian are the Singaporean Indian sex workers, who typically have dark skin tone

${ }^{\mathrm{b}}$ For both Dress and Looks, $1=$ worst and $5=$ best 
Table 3: Transaction Characteristics by Client's Ethnicity

\begin{tabular}{lccccc}
\hline & Chinese & White & Bangladeshi & Indian & All \\
\hline Mean Rating(1=dislike, 5=like most) & 4.16 & 3.93 & 3.15 & 2.08 & \\
\hline Initial Price (S\$) & 73.80 & 91.22 & 49.04 & 67.14 & 71.28 \\
Initial Price (Bargain Successful) & 73.88 & 91.13 & 47.45 & 64.62 & 72.13 \\
Transaction Price & 68.07 & 81.34 & 43.74 & 57.69 & 65.78 \\
Sex Worker Approaching First & 72.8 & 91.8 & 67.3 & 42.9 & 71.9 \\
Bargain Fails & 4.2 & 1.0 & 24.0 & 25.7 & 11.8 \\
\hline Oral Sex & 76.1 & 89.6 & 33.0 & 62.0 & 67.2 \\
Anal Sex & 4.9 & 45.8 & 1.9 & 8.0 & 15.0 \\
Duration of Service & 60 & 85 & 35 & 40 & 45 \\
Sweet Talk(1=least, 5=most) & 2.08 & 2.69 & 1.58 & 1.85 & 2.08 \\
\hline \hline
\end{tabular}

${ }^{1}$ Top line baseed on up to 174 observations. Remaining rows based on up to 677 transactions in which the sex worker was the first to suggest a price. 
Table 4: Log Initial Price by Client Ethnicity

\begin{tabular}{lcccccc}
\hline & $(1)$ & $(2)$ & $(3)$ & $(4)$ & $(5)$ & $(6)$ \\
\hline Ethnicity (Base=Chinese) & & & & & & \\
White & $0.103^{* *}$ & $0.127^{* *}$ & $0.121^{* *}$ & $0.132^{* *}$ & $0.130^{* *}$ & $0.143^{* * *}$ \\
& $(0.043)$ & $(0.052)$ & $(0.051)$ & $(0.055)$ & $(0.062)$ & $(0.040)$ \\
Bangladesh & $-0.144^{* * *}$ & $-0.186^{* * *}$ & $-0.139^{* * *}$ & $-0.133^{* * *}$ & $-0.123^{* *}$ & $-0.135^{* * *}$ \\
& $(0.033)$ & $(0.040)$ & $(0.043)$ & $(0.044)$ & $(0.049)$ & $(0.033)$ \\
Indian & 0.019 & 0.015 & 0.022 & 0.031 & 0.013 & -0.035 \\
& $(0.034)$ & $(0.040)$ & $(0.039)$ & $(0.040)$ & $(0.044)$ & $(0.034)$ \\
Only Sex Worker & Yes & Yes & Yes & Yes & Yes & No \\
Makes 1st Offer & & & & & & \\
Dummies for missing & Yes & No & Yes & Yes & - & Yes \\
Sex Acts & No & No & Yes & Yes & Yes & No \\
Sex Venue & No & No & No & Yes & Yes & No \\
Service Duration & No & No & No & No & Yes & No \\
\hline $\mathrm{N}$ & 676 & 548 & 525 & 513 & 413 & 810 \\
$\mathrm{R}^{2}$ Within & 0.522 & 0.521 & 0.607 & 0.616 & 0.598 & 0.454 \\
$\mathrm{R}^{2}$ Between & 0.072 & 0.280 & 0.002 & 0.000 & 0.000 & 0.336 \\
$\mathrm{R}^{2}$ Overall & 0.221 & 0.301 & 0.180 & 0.198 & 0.245 & 0.294 \\
\hline
\end{tabular}

${ }^{1}$ All regressions include sex worker fixed effects and control for additional dummy variables for Malay, Middle Eastern, East Asian, and black American, a quadratic in client's perceived age, dummies for repeat customer, tourist, dresses well, dress not noticed, customer attractive, attractiveness not noticed, and "sweet talk" above average.

${ }^{2}$ Dummies for missing information on client age, dress and attractiveness included where noted

${ }^{3}$ Sex act dummies: 8 combinations of sex acts plus "not reported."

4 - No observations missing client age, repeat customer or tourist. 
Table 5: Log Final Price by Client Ethnicity

\begin{tabular}{lcccccc}
\hline & $(1)$ & $(2)$ & $(3)$ & $(4)$ & $(5)$ & $(6)$ \\
\hline Ethnicity (Base=Chinese) & & & & & & \\
White & $0.145^{* * *}$ & $0.182^{* * *}$ & $0.153^{* * *}$ & $0.152^{* * *}$ & $0.159^{* * *}$ & $0.181^{* * *}$ \\
& $(0.043)$ & $(0.056)$ & $(0.052)$ & $(0.055)$ & $(0.058)$ & $(0.037)$ \\
Bangladesh & $-0.125^{* * *}$ & $-0.172^{* * *}$ & $-0.110^{* *}$ & $-0.118^{* * *}$ & $-0.141^{* * *}$ & $-0.132^{* * *}$ \\
& $(0.035)$ & $(0.045)$ & $(0.044)$ & $(0.045)$ & $(0.046)$ & $(0.032)$ \\
Indian & 0.014 & 0.008 & 0.024 & 0.024 & 0.015 & 0.008 \\
& $(0.037)$ & $(0.045)$ & $(0.040)$ & $(0.040)$ & $(0.041)$ & $(0.034)$ \\
Only Sex Worker & Yes & Yes & Yes & Yes & Yes & No \\
Makes 1st Offer & & & & & & \\
Dummies for missing & Yes & No & Yes & Yes & - & Yes \\
Sex Acts & No & No & Yes & Yes & Yes & No \\
Sex Venue & No & No & No & Yes & Yes & No \\
Service Duration & No & No & No & No & Yes & No \\
\hline $\mathrm{N}$ & 596 & 469 & 524 & 513 & 413 & 709 \\
$\mathrm{R}^{2}$ Within & 0.506 & 0.496 & 0.546 & 0.559 & 0.589 & 0.481 \\
$\mathrm{R}^{2}$ Between & 0.025 & 0.282 & 0.015 & 0.006 & 0.007 & 0.269 \\
$\mathrm{R}^{2}$ Overall & 0.157 & 0.265 & 0.121 & 0.144 & 0.232 & 0.239 \\
\hline 1 & & & & & & \\
\hline
\end{tabular}

${ }^{1}$ All regressions include sex worker fixed effects and control for additional dummy variables for Malay, Middle Eastern, East Asian, and black American, a quadratic in client's perceived age, dummies for repeat customer, tourist, dresses well, dress not noticed, customer attractive, attractiveness not noticed, and "sweet talk" above average.

${ }^{2}$ Dummies for missing information on client age, dress and attractiveness included where noted.

${ }^{3}$ Sex act dummies: 8 combinations of sex acts plus "not reported."

4 - No observations missing client age, repeat customer or tourist. 
Table 6: Did Sex Worker Approach Client? By Client Ethnicity

\begin{tabular}{lcccc}
\hline & $(1)$ & $(2)$ & $(3)$ & $(4)$ \\
& Fixed Effect Logit & Logit & Fixed Effect Logit & Logit \\
\hline Ethnicity (Base=Chinese) & & & & \\
White & $1.515^{*}$ & 1.244 & 0.574 & 0.769 \\
& $(0.842)$ & $(0.772)$ & $(0.632)$ & $(0.662)$ \\
& & {$[0.208]$} & & {$[0.138]$} \\
Bangladesh & -0.484 & -0.447 & -0.423 & -0.364 \\
& $(0.481)$ & $(0.404)$ & $(0.420)$ & $(0.390)$ \\
& & {$[-0.075]$} & & {$[-0.065]$} \\
Indian & $-1.434^{* * *}$ & $-1.271^{* * *}$ & $-1.621^{* * *}$ & $-1.499^{* * *}$ \\
& $(0.469)$ & $(0.373)$ & $(0.412)$ & $(0.365)$ \\
& & {$[-0.213]$} & & {$[-0.268]$} \\
Only Sex Worker & Yes & Yes & No & No \\
Makes 1st Offer & & & & No \\
Sex Worker Characteristics & No & Yes & 595 & 650 \\
\hline N & 483 & 586 & 595 & -345.006 \\
\hline Likelihood & -154.849 & -294.156 & -202.402 &
\end{tabular}

${ }^{1}$ All estimates include dummy variables for Malay, Middle Eastern, East Asian, and black American, a quadratic in client's perceived age, dummies for repeat customer, tourist, dresses well, dress not noticed, customer attractive, and attractiveness not noticed. Dummies for missing information on client age, dress and attractiveness also included.

${ }^{2}$ Sex worker characteristics: quadratic in age, quadratic in experience,four country of origin dummies, marital status, education, beauty and English skills dummies.

${ }^{3}$ Fixed effects logit drops sex workers who always or never approached clients. Their transactions and other cases where success/failure are perfectly predicted are excluded from N.

${ }^{4}$ Standard errors in parentheses, clustered on sex worker in columns 2 and 4. Marginal effects in brackets. 
Table 7: Bargaining Failed By Client Ethnicity

\begin{tabular}{lcccc}
\hline & $(1)$ & $(2)$ & $(3)$ & $(4)$ \\
& Fixed Effect Logit & Logit & Fixed Effect Logit & Logit \\
\hline Ethnicity (Base=Chinese) & & & & \\
White & -2.073 & -1.455 & $-1.812^{*}$ & -1.753 \\
& $(1.515)$ & $(1.420)$ & $(1.094)$ & $(1.287)$ \\
& & {$[-0.139]$} & & {$[-0.181]$} \\
Bangladesh & $1.951^{* *}$ & $2.114^{* * *}$ & $1.358^{* *}$ & $1.584^{* * *}$ \\
& $(0.781)$ & $(0.543)$ & $(0.632)$ & $(0.507)$ \\
& & {$[0.202]$} & & {$[0.164]$} \\
Indian & $1.705^{* *}$ & $1.886^{* * *}$ & $1.265^{* *}$ & $1.479^{* * *}$ \\
& $(0.743)$ & $(0.519)$ & $(0.589)$ & $(0.471)$ \\
& & {$[0.181]$} & & {$[0.153]$} \\
Only Sex Worker & Yes & Yes & No & No \\
Makes 1st Offer & & & & \\
Sex Worker Characteristics & No & Yes & No & Yes \\
\hline N & 338 & 563 & 438 & 627 \\
Likelihood & -73.253 & -171.722 & -101.944 & -205.423 \\
\hline
\end{tabular}

${ }^{1}$ All estimates include dummy variables for Malay, Middle Eastern, East Asian, and black American, a quadratic in client's perceived age, dummies for repeat customer, tourist, dresses well, dress not noticed, customer attractive, and attractiveness not noticed. Dummies for missing information on client age, dress attractiveness and "sweet talk" above average also included.

${ }^{2}$ Sex worker characteristics: quadratic in age, quadratic in experience,four country of origin dummies, marital status, education, beauty and English skills dummies.

${ }^{3}$ Fixed effects logit drops sex workers who always or never approached clients. Their transactions and other cases where success/failure are perfectly predicted are excluded from $\mathrm{N}$.

${ }^{4}$ Standard errors in parentheses, clustered on sex worker in columns 2 and 4. Marginal effects in brackets. 